\title{
Temporal and Topographic Profiles of Tissue Hypoxia Following Transient Focal Cerebral Ischemia in Rats
}

\author{
Takahisa NOTO ${ }^{1}$, , Yasuhisa FURUICHI ${ }^{1)}$, Masayuki ISHIYE ${ }^{1)}$, Nobuya MATSUOKA ${ }^{1)}$, Ichiro ARAMORI ${ }^{1)}$, \\ Seitaro MUTOH $^{1)}$, Takehiko YANAGIHARA ${ }^{2)}$ and Noboru MANABE ${ }^{3)}$ \\ ${ }^{1)}$ Medicinal Biology Research Laboratories, Astellas Pharmaceutical Inc., 2-1-6 Kashima, Yodogawa-ku, Osaka 532-8514, ${ }^{2)}$ Osaka \\ Neurological Research Institute, 1-6-18-202 Minamiichioka, Minato-ku, Osaka 552-0011 and ${ }^{3)}$ Research Unit for Animal Life Sciences, \\ Animal Resource Science Center, The University of Tokyo, 3145 Ago, Ibaraki-Iwama 319-0206, Japan
}

(Received 26 November 2005/Accepted 7 April 2006)

\begin{abstract}
Intravascular accumulation of blood cells after brain ischemia-reperfusion can cause obstruction of cerebral blood flow and tissue hypoxia/ischemia as a consequence. In the present study, we examined temporal and topographic changes of tissue hypoxia/ ischemia after occlusion of the middle cerebral artery (MCA) for $60 \mathrm{~min}$ in rats with immunohistochemical staining for hypoxia (2nitroimidazole hypoxia marker: hypoxyprobe-1 adducts). Our results showed that tissue hypoxia expressed as positive staining for hypoxyprobe-1 adducts preceded neuronal degeneration. Platelets and granulocytes were detected close to the hypoxyprobe-1 adducts positive area. These results suggested that the hypoxic environment could persist even after reperfusion of MCA, because of vascular obstruction with accumulation of platelets and granulocytes.
\end{abstract}

KEY WORDS: granulocyte, hypoxia, immunohistochemistry, platelet, rat.

J. Vet. Med. Sci. 68(8): 803-807, 2006

It is well known that microvascular perfusion defects occur after occlusion and reperfusion in transient focal ischemia [12]. Intravascular obstruction with local activation of granulocytes and platelets has been implicated in the formation of perfusion defects [5], and it has been assumed that these occlusive events bring about tissue hypoxia and lead to injury of neurons. Treatment with antibodies against ICAM-1 or CD11b/CD18 has been shown to decrease the number of myeloperoxidase positive cells, and reduce the volume of infarction in a rat transient middle cerebral artery (MCA) occlusion model [4]. Similarly, platelets aggregation inhibitors have been reported as powerful neuroprotectants after transient MCA occlusion $[1,3]$. However, there is no information available regarding the relationship between intravascular occlusion and hypoxic environment, because of a lack of appropriate technique to demonstrate the spatial distribution of hypoxic region.

With recent development of 2-nitroimidazole hypoxia markers (hypoxyprobe-1), however, it is now possible to detect the distribution of tissue hypoxia by using immunohistochemical technique [9]. Hypoxyprobe-1, given to animals before sacrifice, forms protein adducts in hypoxic cells $\left(\mathrm{pO}_{2}<10 \mathrm{mmHg}\right.$ at $\left.37^{\circ} \mathrm{C}\right)$, and the protein adducts can be visualized with a monoclonal antibody. In the present work, we investigated tissue hypoxia after transient focal ischemia in rats by using immunohistochemical technique, and examined its relationship to platelets and granulocytes accumulation in microvessels.

\section{MATERIALS AND METHODS}

Experiments were carried out using male Wistar rats (810 week-old, 300-395 g) purchased from Charles River Japan (Hino, Japan). This study was approved by the Exper- imental Laboratory Animal Committee of Fujisawa Pharmaceutical Co., Ltd.

The procedure for transient MCA occlusion was as described by Koizumi et al. [11]. Briefly, each rat was anesthetized with $4.0 \%$ halothane in oxygen-nitrogen (30\% oxygen and $70 \%$ nitrogen). A mixture of $1.5 \%$ halothane and oxygen-nitrogen was used to maintain anesthesia during operation. Each animal was placed in the supine position and a median incision was made in the skin of the neck. The right common carotid artery (CCA) was carefully exposed without damage to the vagus nerve. The right external carotid artery (ECA), internal carotid artery (ICA) and CCA were carefully isolated and maintained in a "Y" shape using a silk thread. The right ECA and CCA were permanently ligated, and an incision to insert a piece of monofilament was made at the bifurcation. The monofilament was made of 4-0 nylon surgical suture (Nicchou, Tokyo, Japan), 19 $\mathrm{mm}$ in length, and was coated with silicone (Xantopren L; Heraeus Kulzer, Dormagen, Germany) mixed with a hardener (Optosil; Heraeus Kulzer) to thicken the distal $5 \mathrm{~mm}$ to about $0.4 \mathrm{~mm}$ in diameter. The proximal tip of the monofilament was heated, creating a globular stopper for easy removal of the monofilament. The monofilament was inserted into the lumen of the ICA. In this position, the monofilament can pass through the origin of the MCA and thereby occlude it. The silk suture around the ICA was tied to fixate the monofilament. The neck wound was closed and the animal was allowed to recover from anesthesia. One hour after MCA occlusion, each animal was re-anesthetized and the neck wound was re-opened. The monofilament was carefully removed to resume blood flow to the MCA and the neck wound was closed again. Neurological deficits such as forelimb flexion and circling to the left were noted following recovery from anesthesia [2]. Animals with no neuro- 
logical deficits (approximately $5 \%$ of animals) were excluded from the experiment.

Each rat received an intraperitoneal injection of hypoxyprobe-1 in saline $(60 \mathrm{mg} / \mathrm{kg}$; Chemicon, Temecula, U.S.A.) $1 \mathrm{hr}$ before sacrifice.

One, 3, 9 and $24 \mathrm{hr}$ after MCA occlusion, each rat was anesthetized and perfused with physiological saline containing $10 \mathrm{U} / \mathrm{m} l$ heparin ( $\mathrm{n}=5$ in each time point). Brain was removed, rapidly frozen by immersion in isopentane at $-70^{\circ} \mathrm{C}$ and sliced into $5 \mu \mathrm{m}$ sections at the level of the caudate putamen. Endogenous peroxidase activity was inhibited by incubation in $0.3 \% \mathrm{H}_{2} \mathrm{O}_{2}$ in PBS containing $0.1 \%$ sodium azide for $10 \mathrm{~min}$. Background signals were blocked by incubating tissue sections in PBS containing 10\% normal donkey serum for $10 \mathrm{~min}$. Tissue sections were then incubated for $1 \mathrm{hr}$ at room temperature $\left(23-25^{\circ} \mathrm{C}\right)$ with antiMAP2 (1:1,000 dilution; Chemicon) or anti-hypoxyprobe-1 antibody (1:500 dilution; Chemicon). After washing, tissue sections were incubated for $30 \mathrm{~min}$ at room temperature with HRP-conjugated anti-mouse IgG (1:150 dilution; Jackson laboratories, Bar Harbor, U.S.A.). The presence of antibody was detected with $0.05 \%$ diaminobenzidine tetrahydrochloride (DAB) and tissue sections were counterstained with hematoxylin.

After endogenous blocking and incubation with $10 \%$ normal donkey serum, tissue sections were incubated for $1 \mathrm{hr}$ at room temperature with anti-rat CD61 (1:50 dilution; Pharmingen, San Diego, U.S.A.) for detection of platelets, or antihuman myeloperoxidase (MPO, 1:1,000 dilution; DAKO, Glostrup, Denmark) for detection of granulocytes. After washing, the slides were incubated with alkaline phosphatase-conjugated anti-mouse IgG (1:150 dilution, Jackson laboratories), or alkaline phosphatase-conjugated anti-rabbit IgG (1:150 dilution; Jackson laboratories) for $30 \mathrm{~min}$ at room temperature, respectively. The presence of each antibody was detected with BCIP/NBT solution (DAKO). After washing with $0.1 \%$ Triton X-100 in PBS, tissue sections were incubated with biotin-conjugated antihypoxyprobe-1 antibody, and then with streptoavidin HRP (1:1,000; dilution Pharmingen) before visualization with DAB. The number of CD61 positive spots and MPO positive cells were semiquantitatively evaluated in three regions; the ischemic core of the cortex, the ischemic penumbra of the cortex, and the caudate putamen, as indicated in Fig. 1. In each region, six microphotographs $(\times 400)$ were taken and the number of positive cells were counted and expressed as number $/ \mathrm{mm}^{2}$.

\section{RESULTS}

Representative photographs stained with anti-MAP2 and anti-hypoxyprobe-1 antibody are shown in Fig. 2. Ischemic neuronal damage expressed as loss of MAP2 immunoreactivity was already detected in the caudate putamen at $1 \mathrm{hr}$ following MCA occlusion (Fig. 2a). However, no apparent loss of MAP2 immunoreactivity was observed in the cortex even $3 \mathrm{hr}$ after MCA occlusion (Fig. 2b). At $9 \mathrm{hr}$ after MCA

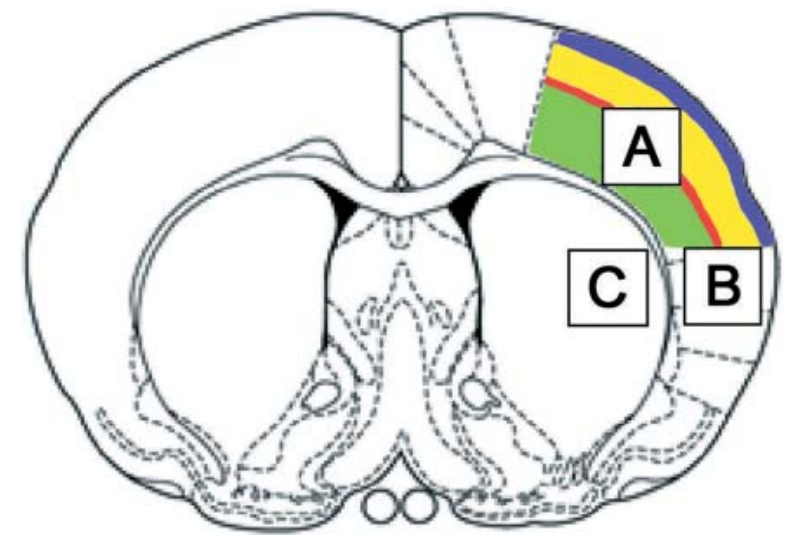

Fig. 1. Schematic Illustration of the brain regions. A; the ischemic penumbra of the cortex, $\mathrm{B}$; the ischemic core of the cortex, and $\mathrm{C}$; the ischemic core of the caudate putamen. Purple zone; layer I, Yellow zone; layer II-III, Red zone; layer IV, Yellow-green zone; layer V-VI.

occlusion, the area lacking MAP2 immunoreactivity was detected in the cortex mainly within layer I/II (Fig. 2c), which gradually expanded and reached the border supplied by the anterior cerebral artery (ACA) at $24 \mathrm{hr}$ (Fig. 2d). Hypoxyprobe-1 adducts were intensely visualized in the cortex and the caudate putamen $1 \mathrm{hr}$ after MCA occlusion (Fig. 2e). At $3 \mathrm{hr}$ after MCA occlusion, the hypoxyprobe-1 immunoreactivity remained in the cortex, more in layer I/II, and the lateral half of the caudate putamen (Fig. 2f). At $9 \mathrm{hr}$ after MCA occlusion, the hypoxyprobe-1 immunorective region in the cortex expanded to layer III to VI (Fig. 2g), and the hypoxyprobe-1 immunoreactivity was seen at the border with and without MAP-2 immunoreactivity seen in Fig. 2c. At $24 \mathrm{hr}$ after MCA occlusion, the hypoxyprobe- 1 immunoreactivity was observed at the border supplied by ACA in the cortex, but scarcely observed in the caudate putamen (Fig. 2h). There was no hypoxyprobe-1 immunoreactivity in the contralateral hemisphere. Temporal profiles of MAP2 immunoreactive area and hypoxyprobe-1 positive area in the ischemic penumbra of the cortex were summarized in Table 1. Considerable individual variety was not seen.

Temporal profiles of CD61 positive spots (platelets) and MPO positive cells (granulocytes) were summarized in Table 2. Platelets were already present $1 \mathrm{hr}$ after MCA occlusion in all regions and became more intense, peaking at $24 \mathrm{hr}$. Granulocytes were recognized beginning $3 \mathrm{hr}$ after MCA occlusion, and diffusely observed at $24 \mathrm{hr}$. Double immunostaining showed that platelets were mainly observed in layer I/II of the cortex at $3 \mathrm{hr}$ (Fig. 3a), but changed the location to layer III to VI at $9 \mathrm{hr}$ after MCA occlusion (Fig. 3b). Along with changes in the location with accumulation of platelets, the area with hypoxyprobe-1 adducts also moved. At $24 \mathrm{hr}$ after MCA occlusion, platelets were mainly located near the area with hypoxyprobe-1 adducts (Fig. 3c). Double immunostaining for granulocytes and hypoxyprobe-1 adducts showed that a number of granu- 


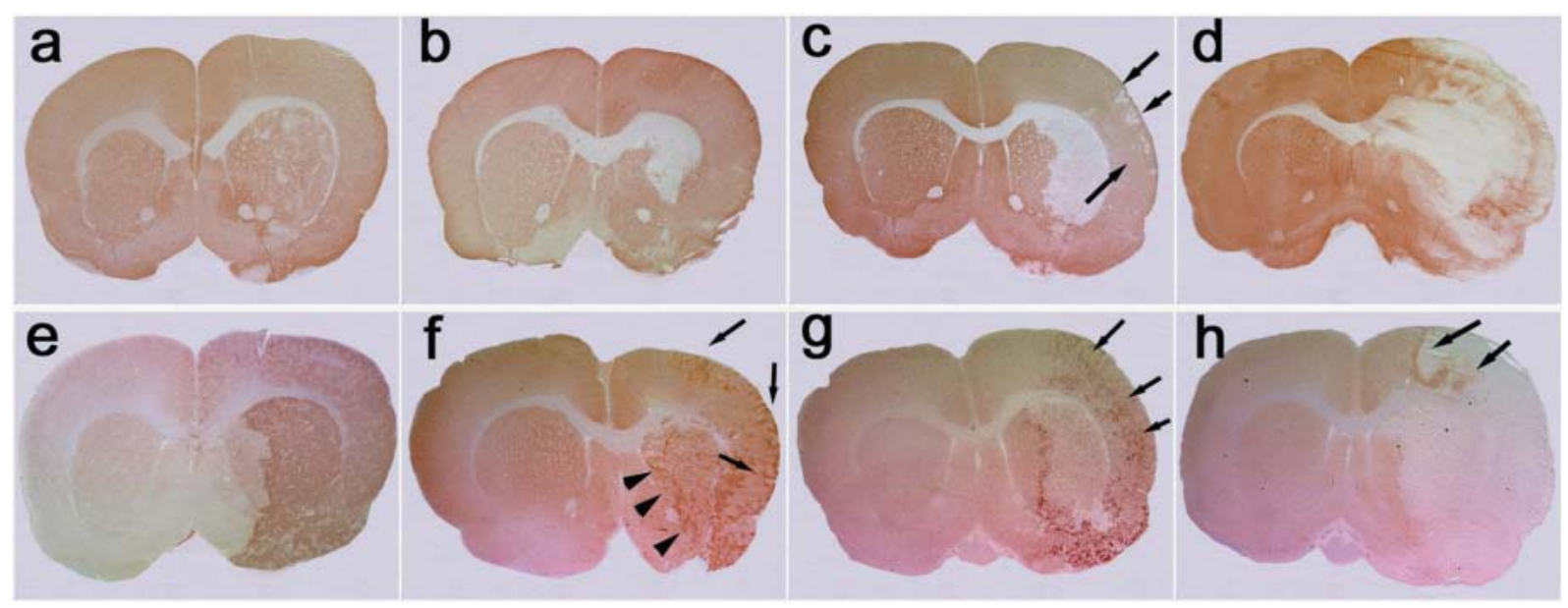

Fig. 2. Immunostaining for MAP2 and hypoxyprobe-1. Photographs in the upper row and the lower row show MAP2 immunostaining and hypoxyprobe-1 immunostaining, respectively. (a) and (e): $1 \mathrm{hr}$ after MCA occlusion. (b) and (f): $3 \mathrm{hr}$ after MCA occlusion. (c),and (g): $9 \mathrm{hr}$ after MCA occlusion. (d), and (h): $24 \mathrm{hr}$ after MCA occlusion. Arrows in (c) indicate the area with loss of MAP2 immunoreactivity in the cortex. Arrows in (f) indicate the hypoxyprobe-1 positive area in layer I/II in the cortex. Arrowheads in (f) indicate the hypoxyprobe-1 immunoreactivity in the lateral half of the caudate putamen. Arrows in (g) indicate the hypoxyprobe-1 positive area in layer III to VI in the cortex. Arrows in (h) indicate the hypoxyprobe-1 immunoreactivity in the penumbra of the cortex.

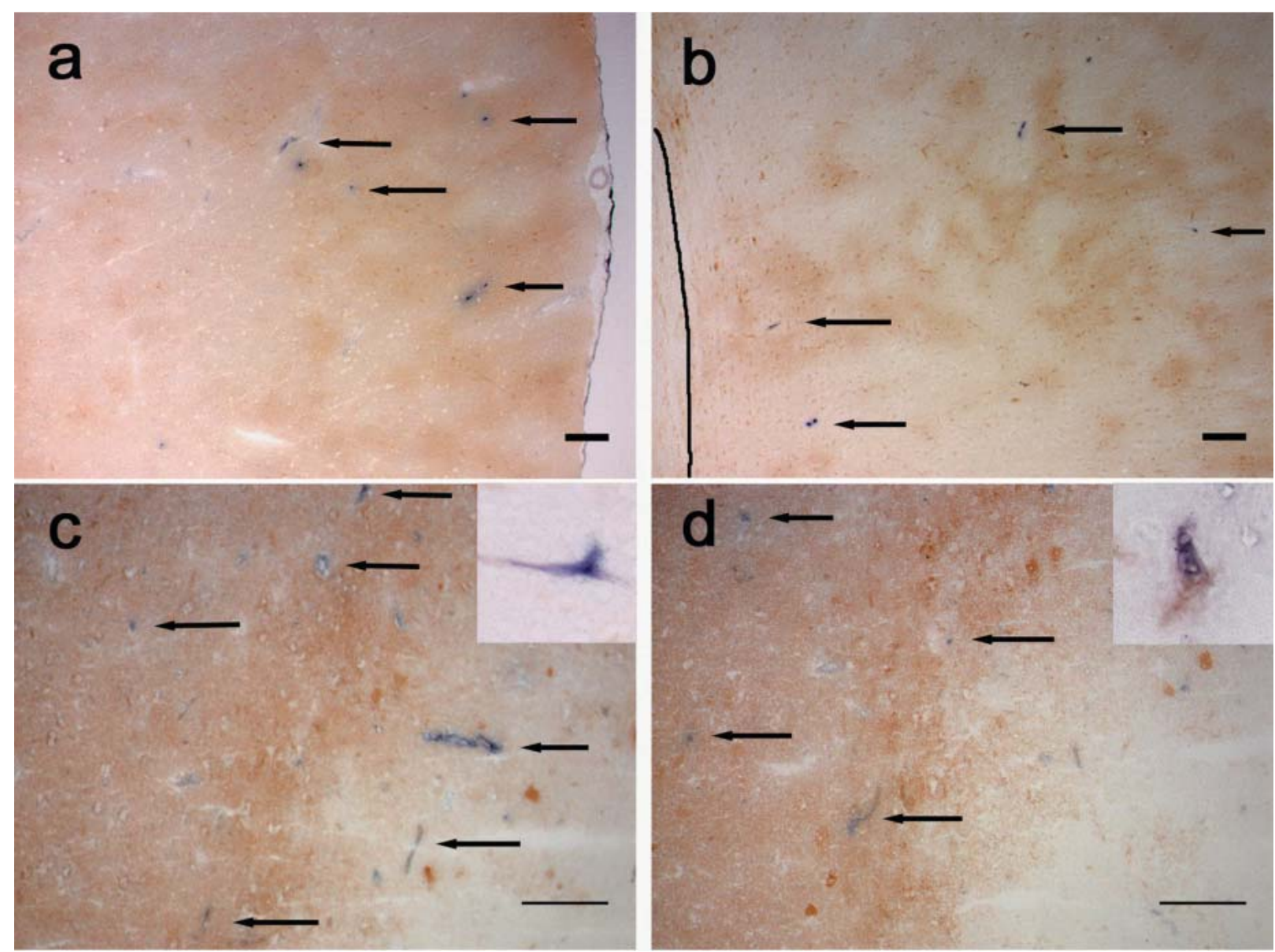

Fig. 3. Double immunostaining for CD61/hypoxyprobe-1 adducts or myeloperoxidase (MPO)/hypoxyprobe-1 adducts in the penumbra of the cortex. CD61 and MPO are stained blue and hypoxyprobe-1 is stained brown. Immunostaining for CD61 (arrows) was colocalized with hypoxyprobe-1 in layer I/II at $3 \mathrm{hr}$ after MCA occlusion (a). The area labeled with CD61 (arrows) and hypoxyprobe-1 shifted to layer III to VI at $9 \mathrm{hr}$ after MCA occlusion (b). The drawn line at the left edge of (b) indicates the border between the cortex and the white matter. At $24 \mathrm{hr}$ after MCA occlusion, CD61 positive particles (arrows in c) and MPO positive cells (arrows in d) were detected close to the hypoxyprobe-1 positive area. Insert of (c) and (d) shows high-magnification images of CD61 positive particle and MPO positive cell, respectively. Scale bar $=50 \mu \mathrm{m}$. 
Table 1. Temporal profiles of loss of MAP2 positive area and hypoxyprobe-1 positive area in the cortex after transient MCA occlusion

\begin{tabular}{lccccc}
\hline \multicolumn{6}{c}{ Time after MCA occlusion } \\
\hline hours & 1 & 3 & 9 & 24 \\
\hline No. of animals & & 5 & 5 & 5 & 5 \\
\hline MAP2 & - a) & 5 & 5 & 1 & 0 \\
& + & 0 & 0 & 3 & 0 \\
& ++ & 0 & 0 & 1 & 5 \\
\hline hypoxyprobe-1 & - b) & 0 & 1 & 0 & 0 \\
& + & 0 & 3 & 2 & 0 \\
& ++ & 0 & 1 & 3 & 5 \\
\hline
\end{tabular}

a) -; no loss of immunoreactivity, + ; loss of immunoreactivity mainly within layer I/II, ++; loss of immunoreactivity reached to layer VI.

b) -; no immunoreactivity, +; immunoreactivity mainly within layer I/II, ++; immunoreactivity reached to layer VI.

locytes were also located near the area with hypoxyprobe-1 adducts $24 \mathrm{hr}$ after MCA occlusion (Fig. 3d).

\section{DISCUSSION}

Oxygen plays a key role in cell death of neurons associated with brain ischemia and reperfusion. Oxygen deficit brings metabolic failure, whereas an excess supply of oxygen generates reactive oxygen species. Several reports have shown changes in the interstitial oxygen tension $\left(\mathrm{pO}_{2}\right)$ in the brain during ischemia and reperfusion by using a sensor implanted in the brain tissue $[13,16]$. However, this monitoring technique can not demonstrate topographic changes of $\mathrm{pO}_{2}$ during cerebral ischemia and reperfusion. Recently, nitroimidazoles, compounds known to undergo intracellular metabolism depending on the $\mathrm{pO}_{2}$, have been proposed as a marker of tissue hypoxia [18]. Autoradiographic studies with ${ }^{125} \mathrm{I}$-indoazomycin arabinoside [14] and BMS-181321 [19], compounds, both belonging to nitroimidazoles, have shown that nitroimidazoles accumulated in ischemic tissue after transient MCA occlusion in rats. Positron emission tomography (PET) technique combined with ${ }^{18} \mathrm{~F}$-fluoromisonidazole has been used to identify the penumbra in stroke patients [7, 15]. Hypoxyprobe-1 is a substituted 2-nitroimidazole that is widely used to demonstrate hypoxic conditions in tissue $[8,9]$. Once injected into laboratory animals, hypoxyprobe- 1 is rapidly distributed to all tissues including brain, and forms adducts with proteins in cells having oxygen concentrations less than $14 \mathrm{mM}$, which is equivalent to $\mathrm{pO}_{2}$ of $10 \mathrm{mmHg}$ at $37^{\circ} \mathrm{C}$. Hypoxyprobe- 1 adducts can be detected by immunohistochemical technique combined with the monoclonal antibody recognizing hypoxyprobe-1-protein adducts.

Using the immunohistochemical technique, we were able to provide temporal and topographic changes of hypoxia following cerebral ischemia and reperfusion. In addition, neuronal damage expressed as loss of MAP2 immunoreactivity was examined with serial sections. We demonstrated that the hypoxyprobe- 1 adducts immunoreactivity always preceded the loss of MAP2 immunoreactivity. The present results suggested that tissue hypoxia was not fully restored after reperfusion, and resulted in neuronal damage. We next demonstrated that platelets were constantly present adjacent to the hypoxyprobe-1 positive area. Granulocytes were also densely present near the hypoxyprobe- 1 positive area at 24 $\mathrm{hr}$ after MCA occlusion. Closure of microvasculature with platelets and granulocytes in the infarcted tissue is well documented and is believed to contribute to neuronal degeneration by obstructing blood flow [6]. Decrease of blood flow is followed by lowering of $\mathrm{pO}_{2}$ and neuronal degeneration. Our data clearly demonstrated relationship between intra-

Table 2. Temporal profiles of myeloperoxidase positive cells and CD61 positive particles after transient MCA occlusion

\begin{tabular}{|c|c|c|c|c|c|c|}
\hline & & \multicolumn{3}{|c|}{ Time after MCA occlusion (hours) } & \multirow[b]{2}{*}{9} & \multirow[b]{2}{*}{24} \\
\hline & & & 1 & 3 & & \\
\hline \multirow[t]{6}{*}{ MPO } & A & $\mathrm{IH}$ & $0.0 \pm 0.0$ & $3.0 \pm 2.8$ & $3.7 \pm 1.3$ & $58.9 \pm 11.0$ \\
\hline & & $\mathrm{CH}$ & $0.0 \pm 0.0$ & $1.1 \pm 2.5$ & $0.7 \pm 1.0$ & $0.0 \pm 0.0$ \\
\hline & $\mathrm{B}$ & $\mathrm{IH}$ & $0.0 \pm 0.0$ & $1.1 \pm 1.7$ & $5.2 \pm 3.6$ & $49.6 \pm 22.2$ \\
\hline & & $\mathrm{CH}$ & $0.0 \pm 0.0$ & $0.4 \pm 0.8$ & $0.4 \pm 0.8$ & $0.4 \pm 0.8$ \\
\hline & $\mathrm{C}$ & $\mathrm{IH}$ & $0.0 \pm 0.0$ & $2.6 \pm 3.6$ & $5.2 \pm 5.8$ & $39.6 \pm 16.4$ \\
\hline & & $\mathrm{CH}$ & $0.0 \pm 0.0$ & $0.0 \pm 0.0$ & $0.0 \pm 0.0$ & $0.0 \pm 0.0$ \\
\hline \multirow[t]{6}{*}{ CD61 } & A & $\mathrm{IH}$ & $11.1 \pm 3.5$ & $9.6 \pm 5.6$ & $18.1 \pm 8.6$ & $18.1 \pm 6.2$ \\
\hline & & $\mathrm{CH}$ & $1.9 \pm 1.9$ & $0.7 \pm 1.0$ & $2.2 \pm 0.8$ & $2.6 \pm 2.5$ \\
\hline & B & $\mathrm{IH}$ & $11.9 \pm 6.4$ & $7.4 \pm 4.5$ & $20.4 \pm 8.6$ & $18.1 \pm 6.2$ \\
\hline & & $\mathrm{CH}$ & $2.6 \pm 3.1$ & $0.7 \pm 1.7$ & $2.2 \pm 0.8$ & $1.5 \pm 1.5$ \\
\hline & $\mathrm{C}$ & $\mathrm{IH}$ & $8.9 \pm 5.5$ & $9.6 \pm 5.5$ & $5.6 \pm 3.2$ & $12.6 \pm 3.3$ \\
\hline & & $\mathrm{CH}$ & $2.6 \pm 3.1$ & $0.0 \pm 0.0$ & $1.1 \pm 1.0$ & $0.0 \pm 0.0$ \\
\hline
\end{tabular}

$\mathrm{A}$; the ischemic penumbra of the cortex, B; the ischemic core of the cortex:, $\mathrm{C}$; the ischemic core of the caudate putamen.

$\mathrm{IH}$; ipsilateral hemisphere, $\mathrm{CH}$; contralateral hemisphere.

Data was represented as the mean \pm S.D. for 5 animals in each group. 
vascular plugging and reduced $\mathrm{pO}_{2}$.

Closure of microvasculature is supposed to be induced by the upregulation of adhesion molecules such as ICAM-1, Pselectin, and E-selectin in endothelial cells after ischemia and reperfusion $[10,21]$. Based on the hypothesis that prevention of the expression of adhesion molecules may ameliorate ischemic brain injury, several clinical and preclinical trials have been carried out with anti-adhesion molecule antibodies $[17,20]$. Our results strongly indicate that utilization of hypoxyprobe-1 immunohistochemistry makes it possible to estimate the efficacy of drugs for protection of microcirculation by demonstrating the topographic profile of $\mathrm{pO}_{2}$.

\section{REFERENCES}

1. Abumiya, T., Fitridge, R., Mazur, C., Copeland, B.R., Koziol, J.A., Tschopp, J.F., Pierschbacher, M.D. and Del Zoppo, G.J. 2000. Integrin $\alpha \operatorname{IIb} \beta 3$ inhibitor preserves microvascular patency in experimental acute focal cerebral ischemia. Stroke 31: 1402-1409.

2. Bederson, J.B., Pitts, L.H., Tsuji, M., Nishimura, M.C., Davis, R.L. and Bartkowski, H. 1986. Rat middle cerebral artery occlusion: evaluation of the model and development of a neurologic examination. Stroke 17: 472-476.

3. Belayev, L., Khoutorova, L., Deisher, T.A., Belayev, A., Busto, R., Zhang, Y., Zhao, W. and Ginsberg, M.D. 2003. Neuroprotective effect of SolCD39, a novel platelet aggregation inhibitor, on transient middle cerebral artery occlusion in rats. Stroke 34: 758-763.

4. Chopp, M., Li, Y., Jiang, N., Zhang, R.L. and Postak, J. 1996. Antibodies against adhesion molecules reduce apoptosis after transient middle cerebral artery occlusion in rat brain. J. Cereb. Blood Flow Metab. 16: 578-584.

5. del Zoppo, G.J., Schmid-Schonbein, G.W., Mori, E., Copeland, B.R. and Chang, C.M. 1991. Polymorphonuclear leukocytes occlude capillaries following middle cerebral artery occlusion and reperfusion in baboons, Stroke 22: 1276-1283.

6. del Zoppo, G.J. and Mabuchi, T. 2003. Cerebral microvessel responses to focal ischemia. J. Cereb. Blood Flow Metab. 23: 879-894.

7. Falcao, A.L., Reutens, D.C., Markus, R., Koga, M., Read, S.J., Tochon-Danguy, H, Sachinidis, J., Howells, D.W. and Donnan, G.A. 2004. The resistance to ischemia of white and gray matter after Stroke Ann. Neurol. 56: 695-701.

8. Gardiner, T.A., Gibson, D.S., de Gooyer, T.E., de la Cruz, V.F., McDonald, D.M. and Stitt, A.W. 2005. Inhibition of tumor necrosis factor-alpha improves physiological angiogenesis and reduces pathological revascularization in ischemic retinopathy. Am. J. Pathol. 166: 637-644.

9. Ghafar, M.A., Anastasiadis, A.G., Olsson, L.E., Chichester, P., Kalpan, S.A., Buttyan, R. and Levin, R.M. 2002. Hypoxia and an angiogenic response in the partially obstructed rat bladder.

\section{Lab. Invest. 82: 903-909.}

10. Ishikawa, M., Cooper, D., Russell, J., Salter, J.W., Zhang, J.H., Nanda A. and Granger, D.N. 2003. Molecular determinants of the prothrombogenic and inflammatory phenotype assumed by the postischemic cerebral microcirculation Stroke 34: 17771782.

11. Koizumi, J., Yoshida, Y., Nakazawa, T. and Ooneda, G. 1986. Experimental studies of ischemic brain edema: 1. A new experimental model of cerebral embolism in rats in which recirculation can be introduced in the ischemic area. Jpn. J. Stroke 8: 18.

12. Kozlov, V.I., Alexandrov, P.N., Semchenko, V.V. and Terman, O.A. 1993. Microvascular stasis: structural and functional aspects. pp. 459-471. In: Microcirculatory Stasis in the Brain, (Tomita, M. ed.), Elsevier Science Publishers, Tokyo.

13. Liu, S., Shi, H., Liu, W., Furuichi, T., Timmins, G.S. and Liu, K.J. 2004. Interstitial pO2 in ischemic penumbra and core are differentially affected following transient focal cerebral ischemia in rats. J. Cereb. Blood Flow Metab. 24: 343-349.

14. Lythgoe, M.F., Williams, S.R., Busza, A.L., Wiebe, L., McEwan, A.J., Gadian, D.G. and Gordon, I. 1999. The relationship between magnetic resonance diffusion imaging and autoradiographic markers of cerebral blood flow and hypoxia in an animal stroke model. Magn. Reson. Med. 41: 706-714.

15. Markus, R., Reutens, D.C., Kazui, S., Read, S., Wright, P., Chambers, B.R., Sachinidis, J.I., Tochon-Danguy, H.J. and Donnan, G.A. 2003. Topography and temporal evolution of hypoxic viable tissue identified by ${ }^{18} \mathrm{~F}$-fluoromisonidazole positron emission tomography in humans after ischemic stroke, Stroke 34: 2646-2652.

16. Martinez-Tica, J.F., Berbarie, R., Davenport, P. and Zornow, M.H. 1999. Monitoring brain PO2, PCO2, and $\mathrm{pH}$ during graded levels of hypoxemia in rabbits. J. Neurosurg. Anesthesiol. 11: 260-263.

17. Mocco, J., Choudhri, T., Huang, J., Harfeldt, E., Efros, L., Kringbeil, C., Vexler, V., Hall, W., Zhang, Y., Mack, W., Popilskis, S., Pinsky, D.J. and Connolly, E.S. Jr. 2002. HuEP5C7 as a humanized monoclonal anti-E/P-selectin neurovascular protective strategy in a blinded placebo-controlled trial of nonhuman primate stroke. Circ. Res. 91: 907-914.

18. Nunn, A., Linder, K. and Strauss, H.W. 1995. Nitroimidazoles and imaging hypoxia. Eur. J. Nucl. Med. 22: 265-280.

19. Di Rocco, R.J., Kuczynski, B.L., Pirro, J.P., Bauer, A., Linder, K.E., Ramalingam, K., Cyr, J.E., Chan, Y.W., Raju, N., Narra, R.K., Nowotnik, D.P. and Nunn, A.D. 1993. Imaging ischemic tissue at risk of infarction during stroke. J. Cereb. Blood Flow Metab. 13: 755-762.

20. Sughrue, M.E., Mehra, A., Connolly, E.S. Jr and D'Ambrosio, A.L. 2004. Anti-adhesion molecule strategies as potential neuroprotective agents in cerebral ischemia: A critical review of the literature. Inflamm. Res. 53: 497-508.

21. Zhang, R., Chopp, M., Zhang, Z., Jiang, N. and Powers, C. 1998. The expression of P- and E-selectins in three models of middle cerebral artery occlusion. Brain Res. 785: 207-214. 